\title{
Accounting
}

\section{Working capital, profit and profitability: An absolute and relational study of selected leading Indian pharmaceutical firms}

\begin{abstract}
Anis Ali ${ }^{\mathbf{a}^{*}}$
${ }^{a}$ Assistant Professor, Department of Management, CBAK, Prince Sattam Bin Abdulaziz University, Saudi Arabia

\begin{tabular}{l}
\hline C H R O N I C L E \\
\hline Article history: \\
Received March 182020 \\
Received in revised format May \\
262020 \\
Accepted July 292020 \\
Available online \\
July 292020 \\
\hline Keywords: \\
Working capital \\
Indian pharmaceutical \\
Relational analysis \\
Rank correlation \\
Profitability
\end{tabular}

\section{A B S T R A C T}

The working capital of the business organization is the excess of current assets over current liabilities. The working capital (WC) governs sales of the business organization directly while sales define the profits. Working capital activates the fixed resources and utilizes the factors of production and it is a bases for the production of goods and services. Working capital is the factor that plays a vital role in the enhancement of sales turnover and profits, ultimately. The present study considers and covers the financial data of selected Indian pharmaceutical companies for the period 2013-2018 for the study of the impact of profitability of the working capital on sales and profits. Ratio analysis is the base of the study while some statistical techniques are to be used to get the mutual relationship, trend, and comovement of the WC and sales, earnings before interest, depreciation, and tax (EBIDT), profit before tax (PBT), and profit after tax (PAT) of the selected Indian pharmaceutical companies. The combined inferences of the absolute and relational study explain that the WC governs the profit positively but not proportionately. There is a need to control the indirect expenses or non-manufacturing expenses of the business to enhance the profitability corresponding to WC movement.
\end{abstract}

\section{Introduction}

In a narrow approach, working capital is the excess of current assets over current liabilities of a business organization and utilizes the factor of production to operate the business activities. There are three main size determinants of the business i.e. sales, total resources, and working capital (WC) while WC is the vital size determinant that utilizes the resources to produce goods and services for sale. So, working capital is the factor that activates the resources of the business to run the business activities to get the ultimate objectives of the business organization. Normally, it is expected that the enhancements of the WC increase the profits of the business if there are no constraints available. In the Indian pharmaceutical industry, it is found that the size of the firm governs the profitability and movement sensitivity of size on profitability is much stronger in smaller Indian pharmaceutical companies (Ali, A., 2020). Nastiti et al. (2019) explained that the conservative working capital policy has a positive impact on the profitability of the business. In the Indian pharmaceutical companies, working capital has a positive impact on profitability (Kumar, Srivastava, Sinha, \& Goyal, 2016). Some other recent studies related the Indian pharmaceutical

* Corresponding author

E-mail address: ah.ali@psau.edu.sa (A. Ali) 
industry reflect that the profits or profitability not only governed by the working capital but also affected by research and development ( R\&D), total quality management (TQM), supply chain management (SCM), intellectual capital (IC), global joint ownership (GJO), size, turnover, and structural and human capital. There are so many studies of working capital (WC) and profitability relationship of Indian pharmaceutical companies available but there is lack of combined study of absolute WC and sales, EBIDT, PBT, and PAT, relational study (qualitative study based on ranking correlation of WC and sales, EBIDT, PBT, and PAT of selected Indian pharmaceutical companies), and short-term relative movement of WC to sales, EBIDT, PBT, and PAT ratio. The study will provide insights of relationship, short-term movability trend of the WC and sales, EBIDT, PBT, and PAT.

\section{Literature review}

\subsection{Working capital and profitability positive relationship}

Nguyen, Pham, \& Nguyen (2020) found in their study that the firm can enhance profitability by proper management of working capital i.e. speedy recovery from the debtors, holding, and small payments to the account payables. Mehra (2013), Shari \& Islam (2018) explained in their research that the profitability of the Indian pharmaceutical firms' can be enhanced by reducing the inventory conversion and accounts receivables collection period. The current liabilities of pharmaceutical firms should be more than current liabilities. Boțoc and Anton (2017) found a U-shape relationship between WC management and profitability in high growth firms. They advocated the special focus on working capital management in growing of cash deficit firms. Kumar (2017) revealed the positive effect of working capital on the profitability of the Indian pharmaceutical companies in India. He suggested the enhanced level of working capital to get profitability. Enough working capital utilizes the resources and leads towards profitability. Shah et al. (2018) found an insignificant relationship between WC and return on equity in pharmaceutical companies. They advised managing properly the components of working capital i.e. inventories, marketable securities receivables, and payables to enhance the profitability. Rahaman et al. (2018) observed that the effective management of WC enhances the profitability of pharmaceutical companies in Bangladesh. Efficient working capital management is necessary for the enhancement of the profitability in pharmaceutical companies of Bangladesh (Chowdhury, Alam, Sultana, \& Hamid, 2018). The liquidity ratio or working capital ratio positively significantly affects the profit earning capacity of Indian pharmaceutical companies (Yameen, Farhan, \& Tabash, 2019).

\subsection{Working capital and profitability negative relationship}

Muhammad, Rehman, \& Waqas (2016) observed the tobacco industry of Pakistan and found that there is a negative relationship between WC and profitability. The profitability depends upon the cash conversion cycle of the business organization. The smaller cash conversion cycle affects profitability positively. Phuong and Hung (2020) found a negative relationship between ingredients of WC i.e. receivables, payables, and cash conversion cycle and profitability of the firm. Ofoegbu and Onodugo (2016) explained that the receivables ratio harms the profitability of the firm. Ahmed, Awan, Safdar, Hasnain \& Kamran (2016) found that all variables of the working capital are negatively correlated with the profitability of the Pakistani pharmaceutical companies. In Indian pharmaceutical companies, liquidity or the higher proportional relationship of the current assets and current liabilities is necessary for the higher profitability or the smooth business activities operation (Panigrahi, Raul, \& Gijare, 2018).

\subsection{Weak or no correlation between working capital and profitability}

Joshi (2020) revealed an insignificant relationship between WC indicators and profitability. There was no relationship seen in between profitability and working capital management in the pharmaceutical companies of India (Bhunia, \& Das, 2015). Gupta (2020) advocated the mild and moderate relationship between working capital management and profitability in Indian pharmaceutical firms.

\subsection{Conditional Relationship between working capital and profitability}

There is a strong and positive relationship between financial performance, sound financial position, and working capital provided that the limited investment in account receivables and inventories (Palanisamy, \& Sengottaiyan, 2015; Viswanathan, Palanisamy, \& Mahesh, 2016).

\subsection{Other Factors Affecting profitability and profits}

\subsubsection{Total quality management (TQM) and Supply chain management (SCM)}

Efficient Total quality management governs the operational performance positively in Indian pharmaceutical companies (Sharma, \& Modgil, 2019). The TQM and SCM affect the operational performance in the pharmaceuticals industry of India (Mahajan, 2020). There is a positive relationship between intellectual capital and financial performance of the Indian pharmaceutical industry (Vishnu, \& Gupta, 2014; Ferdaous, \& Rahman, 2017). 


\subsubsection{Intellectual Capital}

Profitability governed by the intellectual capital (IC) in the Indian pharmaceutical industry (Smriti, \& Das, 2017). In the Indian pharmaceutical industry, physical capital and relational capital enhance profitability while there is a positive relationship between IC and profitability (Gupta, Goel, \& Bhatia, 2020; Mehralian, Rajabzadeh, Sadeh, \& Rasekh, 2012).

\subsubsection{Research and Development}

Research and development (R\&D) positively affect total factor productivity (TFP) growth while the foreign-owned pharmaceutical companies were more concerned about R\&D comparatively domestic firms (Sharma, 2012). There is a positive relationship between R \& D and the financial performance of pharmaceutical companies' in India (Jaisinghani, 2016). The level of R \& D activities and other related factors defines the level of export of the Indian pharmaceutical companies (Tyagi, \& Nauriyal, 2017). The leading pharmaceutical companies earn more due to expenditure on enough funds for $\mathrm{R} \& \mathrm{D}$ and technological advancements (Boldeanu, \& Pugna, 2014).

\subsubsection{Size, turnover, global joint ownership, and structural and human capital}

Enough capital is necessary for the investment in resources to uplift the level of production and profits while turnover of pharmaceutical companies can be considered as a strong measurement of the performance (Shivdas, \& Ray, 2017). The global joint venture in the Indian pharmaceutical industry enhances the firm's financial performances but only up to a certain limit (Sivakumar, Roy, Zhu, \& Hanvanich, 2011). The financial performances of the Indian pharmaceutical companies positively affected by the structural and physical capital but not by the human capital of the companies (Narwal, \& Ramandeep, 2014).

\section{Methodology}

The analysis is based on the published data of the selected Indian pharmaceutical companies available on the websites of the concerned companies. There are seven leading Indian pharmaceutical companies namely, Dr. Reddy's Laboratories (Dr), Lupin limited (Lu), Cipla Limited (Ci), Cadila Healthcare Limited (Ca), and Glenmark Pharma Limited (Gl) Sun Pharmaceutical Industries Limited (Su), and Aurobindo Pharma Limited(Ar) selected for the relational study of the working capital (WC) and profits. The base of analysis of the present study is ratio analysis which is to be used in financial statement analysis of the selected Indian pharmaceutical companies. The following ratios are to be used to analyze the relationship of profits with the working capital (WC).
1. Sales to $\mathrm{WC}$ ratio $=\frac{\text { Sales }}{W C} 100$;
3. $\quad$ PBT to $\mathrm{WC}$ ratio $=\frac{P B T}{W C} 100$;
2. EBIDT to $\mathrm{WC}$ ratio $=\frac{E B I D T}{W C} 100$;
4. $\mathrm{PAT}$ to $\mathrm{WC}$ ratio $=\frac{P A T}{W C} 100$;

where, $\mathrm{WC}=$ working capital; $\mathrm{EBIDT}=$ earnings before interest, depreciation, and tax; $\mathrm{PBT}=$ profit before tax; and $\mathrm{PAT}=$ profit after tax. The coefficient of variations of all variables and correlation between WC and sales, EBIDT, PBT, and PAT calculated to get the comparative variability and correlation. The relational co-movement is based on relative ranks of the qualitative relationship of WC and sales to WC, EBIDT to WC, PBT to WC, and PAT of selected Indian pharmaceutical companies. The following formula is to be used to get a qualitative relationship among the selected pharmaceutical companies.

Spearman's Rank Correlation $\left(\mathrm{r}_{\mathrm{s}}\right)=1-\frac{6 * \sum(D * D)}{n(n * n-1)}$,

where, $\mathrm{D}=$ difference of rank, $\mathrm{n}=$ number of variables.

To get the short-term movement sensitivity, the chain based index numbers calculated:

Chain based Index numbers $(\mathrm{CBI})=\frac{V c y}{V p y} 100$

where, Vcy and Vpy, are variable of current year and variable of the previous year, respectively.

\section{Analysis, results and interpretations}

Working capital is the capital that is to be used to run the business activities of the business organization or utilizes the fixed assets of the concern. So, the utilization or the amount of working capital directly affects the production or sales turnover, profits, and movability sales turnover and profits. The relationship between WC and profits can be done in two ways i.e. absolute analysis and relational analysis.

\subsection{Absolute Analysis}

The variability of the variables and the relationship of variables between or among the variables explain the normal relationship or comparative variability of the variables. In business organizations, the working capital govern sales directly while EBIDT, PBT, and PAT, indirectly. In businesses, interest, depreciation, tax and other manufacturing, selling and administrative expenses, 
etc. increases or decreases without the working capital governance, directly. In a manufacturing concern, the relationship of absolute amounts of WC and EBIDT, PBT, and PAT is to be expected high degree or moderate.

Table 1

Variability and correlation between average working capital and sales, EBIT, PBT, and PAT (amounts in Million Rs.) of selected leading pharmaceuticals companies of India

\begin{tabular}{|c|c|c|c|c|c|}
\hline Years & $\mathrm{WC}$ & Sales & EBIDT & PBT & PAT \\
\hline 2013 & 30.656 & 84.662 & 22.200 & 15.347 & 14.568 \\
\hline 2014 & 39.773 & 105.068 & 29.765 & 20.456 & 21.196 \\
\hline 2015 & 43.919 & 136.207 & 33.403 & 24.687 & 22.327 \\
\hline 2016 & 50.150 & 149.810 & 37.261 & 26.380 & 23.765 \\
\hline 2017 & 50.135 & 161.245 & 40.202 & 29.075 & 26.446 \\
\hline 2018 & 54.341 & 160.577 & 33.451 & 20.234 & 17.240 \\
\hline Average & 44.829 & 132.928 & 32.714 & 22.697 & 20.924 \\
\hline$\sigma$ & 8651 & 31521 & 6277 & 4966 & 4349 \\
\hline CV $(\%)$ & 19 & 24 & 19 & 22 & 21 \\
\hline Correlation(r) & & 0.97 & 0.86 & 0.67 & 0.51 \\
\hline
\end{tabular}

Source: Yearly average of amounts (Rs. in Million) of the selected leading Indian pharmaceutical companies form the concerned websites.

From the above absolute analysis of the average of variables extracted from the financial statement of the Indian pharmaceutical companies, it can be explained that there is no significant variability seen in the average variables (WC, sales, EBIDT, PBT, and PAT) of selected Indian pharmaceutical companies. The relationship between the WC and other measures of the profits is expected and normal. The moderate relationship between PAT and PBT is due to indirect expenses i.e. selling, distribution, and administrative expenses, possibly. The selling, distribution, and administrative expenses of selected Indian pharmaceutical companies do not vary perfectly as per the WC movement.

\subsection{Relational Analysis}

The relational analysis considers the qualitative relative study of the selected business organization and concludes the relationship based on variables of a business. In this study, the relational analysis establishes a qualitative relationship between WC and sales, EBIDT, PBT, and PAT of the selected Indian pharmaceutical companies.

\subsubsection{Relational co-movement of $W C$ and sales}

The sales volume of the business organization is directly governed and move as per the level of the working capital provided that demand for the product or services are not a constraint. Normally, a positive and perfect relationship is expected between absolute amounts of working capital (WC) and sales of the business organization. The relational co-movement of WC and sales to working capital (WC) ratio will measure the qualitative relationship of selected business organization based on quantitative rankings of $\mathrm{WC}$ and sales to $\mathrm{WC}$ ratio.

\section{Table 2}

Relational co-movement of working capital and sales to working capital ratio of selected leading pharmaceutical companies of India (2013-18)

\begin{tabular}{ccccccc}
\hline Indian Pharma. Com. & $\mathrm{WC}$ & $\mathrm{R}_{1}$ & Sales to WC Ratio & $\mathrm{R}_{2}$ & $\mathrm{D}\left(\mathrm{R}_{1}-\mathrm{R}_{2}\right)$ & $\mathrm{D}^{2}$ \\
\hline $\mathrm{Dr}$ & 37,184 & 4.0 & 383 & 3.00 & 1.00 & 1.00 \\
$\mathrm{Lu}$ & 55,724 & 2.0 & 246 & 6.00 & -4.00 & 16.00 \\
$\mathrm{Su}$ & 130,960 & 1.0 & 184 & 7.00 & -6.00 & 36.00 \\
$\mathrm{Ci}$ & 41,462 & 3.0 & 306 & 5.00 & -2.00 & 4.00 \\
$\mathrm{Ar}$ & 21,521 & 6.0 & 558 & 2.00 & 4.00 & 16.00 \\
$\mathrm{Ca}$ & 7,593 & 7.0 & 1,186 & 1.00 & 6.00 & 36.00 \\
$\mathrm{Gl}$ & 19,358 & 5.0 & 375 & 4.00 & 1.00 & 1.00 \\
\hline \multicolumn{7}{c}{$\sum\left(\mathrm{D}^{2}\right)$} \\
\hline
\end{tabular}

Source: Average of WC amounts and sales to WC ratio (2013-18) calculated form the financial statements available at concerned websites of selected leading Indian pharmaceutical companies.

Spearman's Rank Correlation $\left(r_{s}\right)=1-\frac{6 * 110}{7(7 * 7-1)}=1-1.96=-0.96$ 
From the above relational co-movement, it is obvious that there is a highly negative co-movement relationship between the average absolute amount of WC and sales to the WC ratio. This implies that the turnover or salability of the pharmaceutical companies with massive investment in WC capital is lesser than the companies with a low amount of working capital. Low demand for the products and underutilization of resources and inefficient management of current assets and current liabilities are the probable reasons for the relatively low salability of the companies with huge WC. The sales to WC ratio sensitivity will explain the sensitivity trend of the Indian pharmaceutical companies.

\section{Sales to WC ratio and sensitivity}

The sensitivity of sales to the WC ratio explains the sensitivity or short-term movement of sales of business organizations in the $\mathrm{WC}$ context. The average sales to WC ratio and short-term movement (CBI) will define the average trend of short term movement.

Table 3

Sales to WC Ratio and sensitivity of Indian pharmaceutical companies

\begin{tabular}{|c|c|c|c|c|c|c|c|c|c|c|c|c|c|c|}
\hline $\begin{array}{c}\text { Pharm. } \\
\text { Com. }\end{array}$ & \multicolumn{2}{|c|}{ Dr } & \multicolumn{2}{|c|}{$\mathrm{Lu}$} & \multicolumn{2}{|c|}{$\mathrm{Su}$} & \multicolumn{2}{|c|}{$\mathrm{Ci}$} & \multicolumn{2}{|c|}{$\mathrm{Ar}$} & \multicolumn{2}{|c|}{$\mathrm{Ca}$} & \multicolumn{2}{|c|}{ Gl } \\
\hline & & & Sales & & Sales & & Sales & & Sales & & Sales & & Sales & \\
\hline Years & $\begin{array}{c}\text { Sales } \\
\text { to WC }\end{array}$ & CBI & $\begin{array}{l}\text { to } \\
\mathrm{WC}\end{array}$ & CBI & $\begin{array}{l}\text { to } \\
\mathrm{WC}\end{array}$ & CBI & $\begin{array}{l}\text { to } \\
\mathrm{WC}\end{array}$ & CBI & $\begin{array}{l}\text { to } \\
\mathrm{WC}\end{array}$ & CBI & $\begin{array}{l}\text { to } \\
\mathrm{WC}\end{array}$ & CBI & $\begin{array}{l}\text { to } \\
\mathrm{WC}\end{array}$ & CBI \\
\hline 2013 & 420 & 100 & 304 & 100 & 135 & 100 & 184 & 100 & 834 & 100 & 906 & 100 & 711 & 100 \\
\hline 2014 & 300 & 71 & 283 & 93 & 131 & 97 & 338 & 183 & 576 & 69 & 1,395 & 154 & 394 & 55 \\
\hline 2015 & 303 & 101 & 285 & 101 & 219 & 167 & 311 & 92 & 565 & 98 & 1,361 & 98 & 362 & 92 \\
\hline 2016 & 320 & 106 & 225 & 79 & 164 & 75 & 1,314 & 422 & 557 & 99 & 1.055 & 77 & 488 & 135 \\
\hline 2017 & 1,114 & 348 & 224 & 99 & 214 & 130 & 274 & 21 & 585 & 105 & 941 & 89 & 500 & 103 \\
\hline 2018 & 400 & 36 & 219 & 98 & 232 & 109 & 241 & 88 & 473 & 81 & 1,682 & 179 & 220 & 44 \\
\hline Av. & 383 & 127 & 246 & 95 & 184 & 113 & 306 & 151 & 558 & 92 & 1.186 & 116 & 375 & 88 \\
\hline Ranks & 3 & 2 & 6 & 5 & 7 & 4 & 5 & 1 & 2 & 6 & 1 & 3 & 4 & 7 \\
\hline
\end{tabular}

Sources: Sales to WC ratio calculated yearly from the available data in financial statements of the concerned Indian pharmaceutical companies.

The analysis of the ranks of the average Sales to WC ratio and its movement trend explains that there is no qualitative relationship $(\mathrm{rs}=0)$ between sales to WC ratio and trend of short-term movement of sale to WC ratio. This reveals that the ratio of utilization of WC in respect of sales does not govern the short movability of sales to the WC ratio in the Indian pharmaceutical industry. Hence, any Indian pharmaceutical company utilizes its WC for maximum sales or production will be fewer sales sensitive in respect to $\mathrm{WC}$.

\subsubsection{Relational co-movement of WC and EBIDT}

The EBIDT of the business organization is directly governed and move as per the level of the sales volume while sales volume governed by the WC provided that demand is not a constraint and there is no restrictions or ceiling limit of the sales of the products of the business organization. So, WC indirectly governs the EBIT of the business organization, if demand, ceiling limit, sales or turnover, and any other inputs are not the constraints. Normally, a positive and high degree relationship is expected between absolute amounts of working capital (WC) and EBIDT of the business organization. The relational co-movement of $\mathrm{WC}$ and EBIDT to the WC ratio will measure the qualitative relationship of selected business organization based on quantitative rankings of WC and EBIDT to WC ratio.

\section{Table 4}

Relational co-movement of working capital and EBIDT to working capital ratio of selected leading pharmaceutical companies of India

\begin{tabular}{|c|c|c|c|c|c|c|}
\hline Indian Pharma. Com. & WC & $\mathrm{R}_{1}$ & Sales to WC Ratio & $\mathrm{R}_{2}$ & $\mathrm{D}\left(\mathrm{R}_{1}-\mathrm{R}_{2}\right)$ & $\mathrm{D}^{2}$ \\
\hline Dr & 37,184 & 4.0 & 87 & 3.00 & 1.00 & 1.00 \\
\hline $\mathrm{Lu}$ & 55,724 & 2.0 & 63 & 5.50 & -3.50 & 12.25 \\
\hline $\mathrm{Su}$ & 130,960 & 1.0 & 60 & 7.00 & -6.00 & 36.00 \\
\hline $\mathrm{Ci}$ & 41,462 & 3.0 & 63 & 5.50 & -2.50 & 6.25 \\
\hline $\mathrm{Ar}$ & 21,521 & 6.0 & 128 & 2.00 & 4.00 & 16.00 \\
\hline $\mathrm{Ca}$ & 7,593 & 7.0 & 256 & 1.00 & 6.00 & 36.00 \\
\hline Gl & 19,358 & 5.0 & 74 & 4.00 & 1.00 & 1.00 \\
\hline \multicolumn{6}{|c|}{$\sum\left(\mathrm{D}^{2}\right)$} & 108.50 \\
\hline
\end{tabular}

Source: Average of WC amounts and EBIDT to WC ratio (2013-18) calculated form the financial statements available at concerned websites of selected leading Indian pharmaceutical companies. 
Spearman's Rank Correlation $\left(r_{s}\right)=1-\frac{6 * 108.50}{7(7 * 7-1)}=1-1.94=-0.94$

From the above relational co-movement, it is obvious that there is a highly negative co-movement relationship between the average absolute amount of WC and EBIDT to the WC ratio. This implies that the EBIDT of the pharmaceutical companies with massive investment in WC is lesser than the companies with a low amount of working capital. At a larger scale of production, proportionately excess manufacturing expenses, underutilization of resources, and inefficient management of current assets and current liabilities are the probable reasons for the relatively low EBIDT of the companies with massive WC. The EBIDT to WC ratio sensitivity will explain the sensitivity trend of the Indian pharmaceutical.

\section{EBIDT to WC ratio and sensitivity}

The sensitivity of EBIDT to the WC ratio explains the sensitivity or short term movement of EBIDT of business organizations in the WC context. The average of EBIDT to WC ratio and short-term movement (CBI) will define the average trend of short term movement.

\section{Table 5}

\section{EBIDT to WC and sensitivity}

\begin{tabular}{|c|c|c|c|c|c|c|c|c|c|c|c|c|c|c|}
\hline \multirow[t]{2}{*}{$\begin{array}{l}\text { Pharm. } \\
\text { Com. }\end{array}$} & \multirow{2}{*}{\multicolumn{2}{|c|}{ Dr }} & \multicolumn{2}{|c|}{$\mathrm{Lu}$} & \multicolumn{2}{|c|}{$\mathrm{Su}$} & \multicolumn{2}{|c|}{$\mathrm{Ci}$} & \multicolumn{2}{|c|}{$\mathrm{Ar}$} & \multicolumn{2}{|c|}{$\mathrm{Ca}$} & \multicolumn{2}{|c|}{$\mathrm{Gl}$} \\
\hline & & & EBIDT & & EBIDT & & EBIDT & & EBIDT & & EBIDT & & EBIDT & \\
\hline Years & to $\mathrm{WC}$ & CBI & to $\mathrm{WC}$ & CBI & to $\mathrm{WC}$ & CBI & to $\mathrm{WC}$ & CBI & to $\mathrm{WC}$ & CBI & to $\mathrm{WC}$ & CBI & to $\mathrm{WC}$ & $\mathrm{CBI}$ \\
\hline 2013 & 100 & 100 & 72 & 100 & 61 & 100 & 52 & 100 & 126 & 100 & 165 & 100 & 145 & 100 \\
\hline 2014 & 75 & 75 & 77 & 107 & 59 & 98 & 78 & 148 & 153 & 121 & 240 & 146 & 72 & 50 \\
\hline 2015 & 75 & 99 & 84 & 109 & 66 & 111 & 63 & 81 & 123 & 81 & 281 & 117 & 67 & 93 \\
\hline 2016 & 84 & 113 & 60 & 72 & 51 & 77 & 252 & 401 & 134 & 109 & 263 & 93 & 94 & 139 \\
\hline 2017 & 209 & 249 & 58 & 97 & 71 & 140 & 50 & 20 & 137 & 102 & 197 & 75 & 112 & 120 \\
\hline 2018 & 70 & 33 & 45 & 77 & 55 & 77 & 46 & 92 & 110 & 81 & 413 & 209 & 41 & 36 \\
\hline Av. & 87 & 112 & 63 & 94 & 60 & 100 & 63 & 140 & 128 & 99 & 256 & 123 & 74 & 90 \\
\hline Ranks & 3 & 3 & 5.50 & 6 & 7 & 4 & 5.50 & 1 & 2 & 5 & 1 & 2 & 4 & 7 \\
\hline
\end{tabular}

Sources: EBIDT to WC ratio calculated yearly from the available data in financial statements of the concerned Indian pharmaceutical companies.

The analysis of the ranks of the average EBIDT to WC ratio and its movement trend explains that there is a negligible positive qualitative relationship ( $\mathrm{rs}=0.13$ ) between EBIDT to WC ratio and trend of short term movement of EBIDT to WC ratio. This reveals that the ratio of utilization of WC in respect of EBIDT does not govern the short-term movability of EBIDT to the WC ratio in the Indian pharmaceutical industry. Hence, any Indian pharmaceutical company utilizes its WC for maximum EBIDT will be less EBIDT sensitive with respect to WC.

\subsubsection{Relational co-movement of WC and PBT}

The PBT of the business organization is directly governed and move as per the level of the EBIDT volume while EBIDT volume governed by the sales provided that demand is not a constraint and there is no restrictions or ceiling limit of the sales of the business organization. WC of the business governs the sales of the business, indirectly. So, WC indirectly governs the PBT of the business organization, if demand, ceiling limit, sales or turnover, and any other inputs are not the constraints, and interest and depreciation of the business organization are negligible. Normally, a positive and high degree relationship is expected in between absolute amounts of WC and PBT of the business organization. The relational co-movement of WC and PBT to WC ratio will measure the qualitative relationship of selected business organization based on quantitative rankings of WC and PBT to $\mathrm{WC}$ ratio.

\section{Table 6}

Relational co-movement of working capital and PBT to working capital ratio of selected leading pharmaceutical companies of India

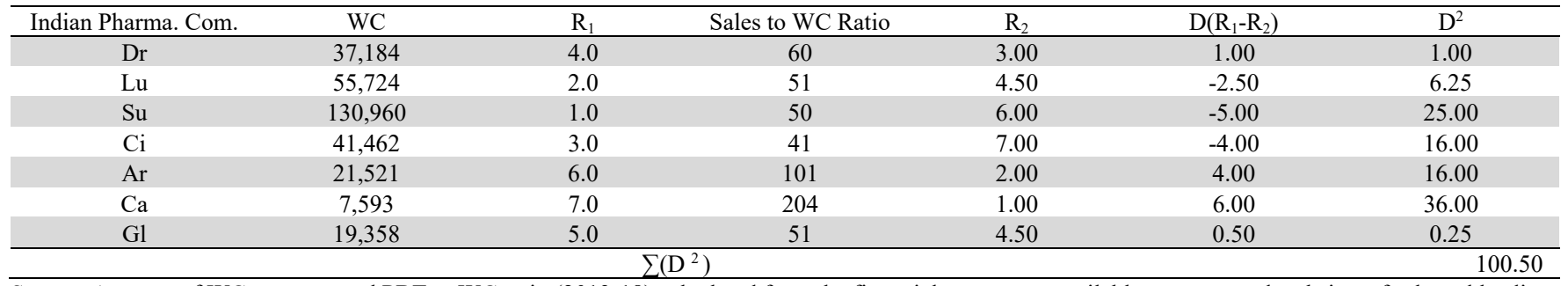

Source: Average of WC amounts and PBT to WC ratio (2013-18) calculated form the financial statements available at concerned websites of selected leading Indian pharmaceutical companies. 
Spearman's Rank Correlation $\left(\mathrm{r}_{\mathrm{s}}\right)=1-\frac{6 * 100.50}{7(7 * 7-1)}=1-1.79=-0.79$

From the above relational co-movement, it is obvious that there is a negative co-movement relationship between the average absolute amount of WC and PBT to the WC ratio. This implies that the PBT of the pharmaceutical companies with massive investment in WC is lesser than the companies with a low amount of working capital. At a larger scale of production, proportionately excess interest and depreciation expenses and inefficient management of current assets and current liabilities are the probable reasons for the relatively low PBT of the companies with massive WC. The PBT to WC ratio sensitivity will explain the sensitivity trend of the Indian pharmaceutical.

\section{PBT to WC ratio and sensitivity}

The sensitivity of PBT to the WC ratio explains the sensitivity or short term movement of PBT of business organizations in the WC context. The average of PBT to WC ratio and short-term movement (CBI) will define the average trend of short term movement.

Table 7

PBT to WC and sensitivity

\begin{tabular}{|c|c|c|c|c|c|c|c|c|c|c|c|c|c|c|}
\hline $\begin{array}{c}\text { Pharm. } \\
\text { Com. }\end{array}$ & \multicolumn{2}{|l|}{$\mathrm{Dr}$} & \multicolumn{2}{|c|}{$\mathrm{Lu}$} & \multicolumn{2}{|c|}{$\mathrm{Su}$} & \multicolumn{2}{|c|}{$\mathrm{Ci}$} & \multicolumn{2}{|c|}{$\mathrm{Ar}$} & \multicolumn{2}{|c|}{$\mathrm{Ca}$} & \multicolumn{2}{|c|}{ Gl } \\
\hline & PBT to & & PBT to & & PBT & & PBT to & & PBT to & & PBT to & & PBT to & \\
\hline Years & WC & CBI & WC & CBI & to $\mathrm{WC}$ & CBI & WC & CBI & WC & CBI & WC & CBI & WC & CBI \\
\hline 2013 & 75 & 100 & 60 & 100 & 57 & 100 & 45 & 100 & 53 & 100 & 115 & 100 & 105 & 100 \\
\hline 2014 & 58 & 77 & 70 & 116 & 56 & 99 & 61 & 137 & 109 & 205 & 184 & 161 & 46 & 44 \\
\hline 2015 & 57 & 98 & 74 & 106 & 52 & 93 & 45 & 74 & 100 & 92 & 228 & 124 & 40 & 88 \\
\hline 2016 & 54 & 94 & 52 & 70 & 42 & 81 & 162 & 362 & 108 & 108 & 226 & 99 & 66 & 163 \\
\hline 2017 & 123 & 229 & 45 & 87 & 60 & 142 & 23 & 14 & 118 & 109 & 157 & 69 & 85 & 130 \\
\hline 2018 & 37 & 30 & 28 & 61 & 38 & 63 & 25 & 111 & 92 & 79 & 325 & 208 & 27 & 31 \\
\hline Av. & 60 & 105 & 51 & 90 & 50 & 96 & 41 & 133 & 101 & 115 & 204 & 127 & 51 & 93 \\
\hline Ranks & 3 & 4 & 4.50 & 7 & 6 & 5 & 7 & 1 & 2 & 3 & 1 & 2 & 4.50 & 6 \\
\hline
\end{tabular}

Sources: PBT to WC ratio calculated yearly from the available data in financial statements of the concerned Indian pharmaceutical companies.

The analysis of the ranks of the average PBT to WC ratio and its movement trend explains that there is a negligible positive qualitative relationship ( $\mathrm{rs}=0.14$ ) between PBT to $\mathrm{WC}$ ratio and trend of short term movement of PBT to WC ratio. This reveals that the ratio of utilization of WC in respect of PBT does not govern the short movability of PBT to the WC ratio in the Indian pharmaceutical industry. Hence, any Indian pharmaceutical company utilizes its WC for maximum PBT will be less PBT sensitive with respect to WC.

\subsubsection{Relational co-movement of WC and PAT}

The PAT of the business organization is directly governed and move as per the level of the PBT volume while PBT governed by the EBIDT and sales provided that demand is not a constraint and there is no restrictions or ceiling limit of the sales of the business organization. WC of the business governs the sales and EBIDT of the business, indirectly. So, WC indirectly governs the PAT of the business organization, if demand, ceiling limit, sales or turnover, and any other inputs are not the constraints, and interest and depreciation of the business organization are negligible. Normally, a positive and high degree relationship is expected between absolute amounts of working capital (WC) and PAT of the business organization. The relational co-movement of WC and PAT to the WC ratio will measure the qualitative relationship of selected business organizations based on quantitative rankings of WC and PAT to the WC ratio.

\section{Table 8}

Relational co-movement of working capital and PBT to working capital ratio of selected leading pharmaceutical companies of India

\begin{tabular}{|c|c|c|c|c|c|c|}
\hline Indian Pharma. Com. & $\mathrm{WC}$ & $\mathrm{R}_{1}$ & Sales to WC Ratio & $\mathrm{R}_{2}$ & $\mathrm{D}\left(\mathrm{R}_{1}-\mathrm{R}_{2}\right)$ & $\mathrm{D}^{2}$ \\
\hline Dr & 37,184 & 4.0 & 46 & 3.00 & 1.00 & 1.00 \\
\hline $\mathrm{Lu}$ & 55,724 & 2.0 & 32 & 6.50 & -4.50 & 20.25 \\
\hline $\mathrm{Su}$ & 130,960 & 1.0 & 37 & 5.00 & -4.00 & 16.00 \\
\hline $\mathrm{Ci}$ & 41,462 & 3.0 & 32 & 6.50 & -3.50 & 12.25 \\
\hline $\mathrm{Ar}$ & 21,521 & 6.0 & 75 & 2.00 & 4.00 & 16.00 \\
\hline $\mathrm{Ca}$ & 7,593 & 7.0 & 233 & 1.00 & 6.00 & 36.00 \\
\hline Gl & 19,358 & 5.0 & 42 & 4.00 & 1.00 & 1.00 \\
\hline \multicolumn{6}{|c|}{$\sum\left(\mathrm{D}^{2}\right)$} & 102.50 \\
\hline
\end{tabular}

Source: Average of WC amounts and PAT to WC ratio (2013-18) calculated form the financial statements available at concerned websites of selected leading Indian pharmaceutical companies. 


$$
\text { Spearman's Rank Correlation }\left(r_{s}\right)=1-\frac{6 * 102.50}{7(7 * 7-1)}, \quad=1-1.83, \quad=-0.83
$$

From the above relational co-movement, it is obvious that there is a high degree negative co-movement relationship between the average absolute amount of WC and PAT to the WC ratio. This implies that the PAT of pharmaceutical companies with massive investment in WC is lesser than the companies with a low amount of working capital. At a larger scale of production, proportionately excess tax expenses, and inefficient management of current assets and current liabilities are the probable reasons for the relatively low PAT of the companies with huge WC. The PAT to WC ratio sensitivity will explain the sensitivity trend of the Indian pharmaceutical.

\section{PAT to WC ratio and sensitivity}

The sensitivity of PAT to the WC ratio explains the sensitivity or short-term movement of PAT of business organizations in the WC context. The average of PAT to WC ratio and short-term movement (CBI) will define the average trend of short-term movement.

\section{Table 9}

PAT to WC and sensitivity

\begin{tabular}{|c|c|c|c|c|c|c|c|c|c|c|c|c|c|c|}
\hline $\begin{array}{c}\text { Pharm. } \\
\text { Com. }\end{array}$ & Dr & & $\mathrm{L}$ & & & & & & & & $\mathrm{C}$ & & & \\
\hline Years & $\begin{array}{c}\text { PAT to } \\
\text { WC }\end{array}$ & CBI & $\begin{array}{c}\text { PAT to } \\
\text { WC }\end{array}$ & $\mathrm{CBI}$ & $\begin{array}{c}\mathrm{PAT} \\
\text { to } \mathrm{WC}\end{array}$ & $\mathrm{CBI}$ & $\begin{array}{c}\text { PAT } \\
\text { to } \mathrm{WC}\end{array}$ & CBI & $\begin{array}{c}\text { PAT to } \\
\text { WC }\end{array}$ & $\mathrm{CBI}$ & $\begin{array}{c}\text { PAT to } \\
\text { WC }\end{array}$ & $\mathrm{CBI}$ & $\begin{array}{c}\mathrm{PAT} \\
\text { to } \mathrm{WC}\end{array}$ & $\mathrm{CBI}$ \\
\hline 2013 & 53 & 100 & 42 & 100 & 40 & 100 & 34 & 100 & 41 & 100 & 41 & 100 & 41 & 100 \\
\hline 2014 & 43 & 81 & 46 & 110 & 31 & 76 & 46 & 136 & 83 & 201 & 132 & 321 & 41 & 100 \\
\hline 2015 & 46 & 107 & 53 & 115 & 43 & 141 & 34 & 74 & 73 & 88 & 131 & 99 & 30 & 73 \\
\hline 2016 & 43 & 93 & 35 & 66 & 33 & 77 & 131 & 386 & 78 & 108 & 126 & 96 & 13 & 45 \\
\hline 2017 & 102 & 237 & 32 & 92 & 52 & 157 & 19 & 15 & 88 & 113 & 151 & 120 & 39 & 290 \\
\hline 2018 & 26 & 26 & 3 & 11 & 22 & 43 & 20 & 106 & 69 & 78 & 207 & 138 & 27 & 68 \\
\hline Av. & 46 & 107 & 32 & 82 & 37 & 99 & 32 & 136 & 75 & 115 & 233 & 145 & 42 & 113 \\
\hline Ranks & 3 & 5 & 6.5 & 7 & 5 & 6 & 6.5 & 2 & 2 & 3 & 1 & 1 & 4 & 4 \\
\hline
\end{tabular}

Sources: PAT to WC ratio calculated yearly from the available data in financial statements of the concerned Indian pharmaceutical companies.

The analysis of the ranks of the average PAT to WC ratio and its movement trend explains that there is a moderate positive qualitative relationship ( $\mathrm{rs}=0.53$ ) between PAT to WC ratio and trend of short term movement of PAT to WC ratio. This reveals that the ratio of utilization of WC in respect of PBT governs positively and moderately the short movability of PAT to the WC ratio in the Indian pharmaceutical industry. Hence, any Indian pharmaceutical company utilizes its WC for maximum PBT will be moderately PBT sensitive in respect of WC.

\section{Discussion}

As expected, the relationship between the WC and other measures of the profits is expected and normal while there is a moderate relationship between PAT and PBT due to indirect expenses i.e. selling, distribution, and administrative expenses, probably. At larger production or a huge WC level, all the non-manufacturing or indirect expenses of selected Indian pharmaceutical companies do not vary perfectly as per the WC movement. The relational qualitative analysis of WC and sales, EBIDT, PBT, and PAT reflects the negativity of selected Indian pharmaceutical companies. This implies that the enhanced level of WC of Indian pharmaceutical companies does not generate sales or other measures of profit, proportionately. Hence, Indian pharmaceutical companies with huge WC are comparatively less productive than the smaller WC Indian pharmaceutical companies. There are no relationship sales to the WC ratio and its trend and very low positive correlation between EBIDT to $\mathrm{WC}$ ratio, $\mathrm{PBT}$ to $\mathrm{WC}$ ratio, and its trend. It reflects that there is no short-term sensitivity relationship between sales, profit measures, and WC. The absolute amount of the WC does not govern the relational profit measures.

\section{Conclusion}

Based on the absolute analysis it can be concluded that there is a positive relationship between absolute amounts of sales, EBIDT, PBT, and WC. The enhancement of WC of the Indian pharmaceutical companies enhances the absolute profits. The relational analysis concludes that the enhancement of WC of the selected Indian pharmaceutical companies decreases the relative profitability. The combined inferences of the absolute and relational study explain that the enhancement of WC increases the profits positively but not proportionately. There is no significant relationship between Sales to WC ratio, EBIDT and WC ratio, PBT, and WC ratio and its short-term movement trend. It reveals that the movement of WC and sales, other measures of profits is irrelevant. There is a moderate relationship between PBT to the WC ratio and its movement trend, which is negligible. So, Indian pharmaceutical companies should increase the WC provided that control on indirect expenses i.e. selling and distribution, and administrative expenses of the business. This study considers only a limited period (2013 to 2018) quantitative data while 
the quantitative data converted into qualitative data for relational or comparative study. There is a need and scope for further studies to consider the indirect expenses and their relation with the WC of the Indian pharmaceutical companies for depth insights of the industry.

\section{Acknowledgment}

The researcher extends his sincere thanks to the Deanship of Scientific Research at Prince Sattam Bin Abdulaziz University for its continuous support and contributions in the field of scientific research.

\section{References}

Ahmed, Z., Awan, M. Z., Safdar, M. Z., Hasnain, T., \& Kamran, M. (2016). A nexus between working capital management and profitability: A case study of pharmaceutical sector in Pakistán. International Journal of Economics and Financial Issues, 6(3S).

Ali, A. (2020). Do the giant players enjoy profitability? Analytical study of Pharmaceutical Industry of India. Talent Development \& Excellence, 12(2s), 3249-3260.

Bhunia, A., \& Das, A. (2015). Underlying relationship between working capital management and profitability of pharmaceutical companies in India. American journal of theoretical and applied business, 1(1), 27-36.

Boldeanu, D. M., \& Pugna, I. B. (2014). The analysis of the influence factors affecting the performance of pharmaceutical companies. Theoretical \& Applied Economics, 21(7), 23-42.

Boțoc, C., \& Anton, S. G. (2017). Is profitability driven by working capital management? Evidence for high-growth firms from emerging Europe. Journal of Business Economics and Management, 18(6), 1135-1155.

Chowdhury, A. Y., Alam, M. Z., Sultana, S., \& Hamid, M. K. (2018). Impact of working capital management on profitability: A case study on pharmaceutical companies of Bangladesh. Journal of Economics, Business and Management, 6(1), 27-35.

Ferdaous, J., \& Rahman, M. M. (2017). The effects of research and development expenditure on firm performance: an examination of pharmaceuticals industry in Bangladesh. Business \& Entrepreneurship Journal, 6(2), 1-20.

Gupta, K., Goel, S., \& Bhatia, P. (2020). Intellectual Capital and Profitability: Evidence from Indian Pharmaceutical Sector. Vision, 24(2), 204-216.

Gupta, N. (2020). A Study on the Effect of Working Capital Management on the Profitability of the Indian Pharmaceutical Companies. Purakala with ISSN 0971-2143 is an UGC CARE Journal, 31(4), 579-591.

Jaisinghani, D. (2016). Impact of R\&D on profitability in the pharma sector: an empirical study from India. Journal of Asia Business Studies. 10(2), 194-210.

Joshi, L. K. (2020). Impact of Working Capital Management on Profitability: An Empirical Evidence from Sun Pharmaceutical Industries Limited. Studies in Indian Place Names, 40(70), 103-110.

Kumar, D.S (2017). Effect of working capital on firm's profitability: a pragmatic study with reference to pharmaceutical companies in India. International Journal of Advanced Research, 5(7), 668-672.

Kumar, S., Srivastava, P., Sinha, S. K., \& Goyal, R. (2016). A study of financial efficiency and liquidity position of Indian pharmaceutical industry special reference to Cipla Ltd. International Journal of Innovations in Engineering and Technology, 7(1), 702-711.

Mahajan, V. (2020). Is productivity of Indian pharmaceutical industry affected with the introduction of product patent act?. Indian Growth and Development Review. 13(1), 227-258.

Mehra, P. (2013). Effect of working capital management on the profitability of the Indian Pharmaceutical sector. International Journal of Enhanced Research in Management and Computer Applications, 2(3), 1-7.

Mehralian, G., Rajabzadeh, A., Sadeh, M. R., \& Rasekh, H. R. (2012). Intellectual capital and corporate performance in Iranian pharmaceutical industry. Journal of Intellectual Capital, 13(1),138-158.

Muhammad, H., Rehman, A. U., \& Waqas, M. (2016). The relationship between working capital management and profitability: A case study of tobacco industry of Pakistan. The Journal of Asian Finance, Economics and Business (JAFEB), 3(2), 13-20.

Narwal, K. Pal, Ramandeep (2014). The Relationship between Intellectual Capital and Financial Performance: An Empirical Study of Indian Pharmaceutical Industry. MERC Global's International Journal of Management, 2(4), $151-169$.

Nastiti, P. K. Y., Atahau, A. D. R., \& Supramono, S. (2019). Working capital management policy: Female top managers and firm profitability. Journal of Management and Business Administration. Central Europe, 27(3), 107-127.

NGUYEN, A. H., PHAM, H. T., \& NGUYEN, H. T. (2020). Impact of working capital management on firm's profitability: Empirical evidence from Vietnam. The Journal of Asian Finance, Economics, and Business, 7(3), 115-125.

Ofoegbu, G. N., \& Onodugo, V. A. (2016). Liquidity management and profit performance of pharmaceutical manufacturing firms listed in Nigeria Stock Exchange. International Journal of Management Sciences and Business Research, 5(7), 1-13.

Palanisamy, A., \& Sengottaiyan, A. (2015). Analysis of working capital position of selected pharmaceutical companies in India. International Journal in Management \& Social Science, 3(8), 97-106.

Panigrahi, C. M. A., Raul, N., \& Gijare, C. (2018). Liquidity and profitability trade-off: A study of Indian pharmaceutical companies. NMIMS Journal of Economics and Public Policy, 3(1). 42-56. 
Phuong, N., \& Hung, D. (2020). Impact of working capital management on firm profitability: Empirical study in Vietnam. Accounting, 6(3), 259-266.

Rahaman, M., Rabbi, I., \& Alam, M. (2018). The impact of working capital management on profitability of elite pharmaceuticals sector in Bangladesh.

Shah, B., Gujar, M. A., \& Sohu, N. U. (2018). The impact of working capital management on profitability: case study of pharmaceutical and chemical firms listed on Karachi stock exchange. International Journal of Economics, Commerce and Management, 6(3), 200-220.

Sharif, M. A., \& Islam, M. R. (2018). Working capital management a measurement tool for profitability: A study on pharmaceutical industry in Bangladesh. Journal of Finance and Accounting, 6(1), 1-10.

Sharma, C. (2012). R\&D and firm performance: evidence from the Indian pharmaceutical industry. Journal of the Asia Pacific Economy, 17(2), 332-342.

Sharma, S., \& Modgil, S. (2019).TQM, SCM and operational performance: an empirical study of Indian pharmaceutical industry. Business Process Management Journal, 26(1), 331-370.

Shivdas, A., \& Ray, S. (2017). Resource utilization by pharmaceutical companies in India: Emphasis on R\&D, labor and capital. In 2017 International Conference on Data Management, Analytics and Innovation (ICDMAI) ,19-23.

Sivakumar, K., Roy, S., Zhu, J., \& Hanvanich, S. (2011). Global innovation generation and financial performance in businessto-business relationships: the case of cross-border alliances in the pharmaceutical industry. Journal of the Academy of Marketing Science, 39(5), 757-776.

Smriti, N., \& Das, N. (2017). Impact of intellectual capital on business performance: evidence from Indian pharmaceutical sector. Polish Journal of Management Studies, 15(1), 232-243.

Tyagi, S., \& Nauriyal, D. K. (2017). Do innovative activities matter to Indian drug and pharmaceutical firms? An application to export performance. Journal of Generic Medicines, 13(4), 193-205.

Vishnu, S., \& Gupta, V. K. (2014).Intellectual capital and performance of pharmaceutical firms in India. Journal of Intellectual Capital, 15(1), 83-99.

Viswanathan, D., Palanisamy, D., \& Mahesh, R. (2016). A comparative study on working capital management of selected pharmaceutical companies in India. Social Sciences, 3(3), 499-511.

Yameen, M., Farhan, N. H., \& Tabash, M. I. (2019). The impact of liquidity on firms' performance: Empirical investigation from Indian pharmaceutical companies. Academic Journal of Interdisciplinary Studies, 8(3), 212-212.

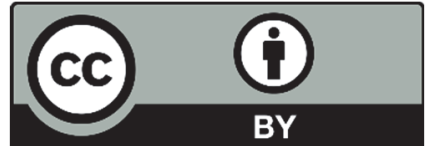

(C) 2020 by the authors; licensee Growing Science, Canada. This is an open access article distributed under the terms and conditions of the Creative Commons Attribution (CC-BY) license (http://creativecommons.org/licenses/by/4.0/). 